\title{
Reconstruction does not reduce tibial translation in the cruciate-deficient knee
}

(1)

\author{
AN IN VIVO STUDY \\ D. J. Beard, D. W. Murray, H. S. Gill, A. J. Price, J. L. Rees, \\ J. Alfaro-Adrián, C. A. F. Dodd \\ From the Nuffield Orthopaedic Centre, Oxford, England
}

W e have assessed the effectiveness of reconstruction of the anterior cruciate ligament (ACL) in reducing functional tibial translation (TT).

The gait of 11 ACL-deficient patients was studied using Vicon equipment before and after surgery. Measurements of the angle between the patellar tendon and the long axis of the tibia were obtained in order to calculate $\mathrm{TT}$ in the sagittal plane relative to the uninjured limb during standing and walking.

Before surgery, patients did not show abnormal TT on the injured side, but after surgery significant anterior TT was found in the operated limb for every parameter of gait.

Abnormal anterior TT occurring during activity does not seem to be reduced by reconstruction; rather, it increases. It may be that the increased translation results from relaxation of excess contraction of the hamstring muscles, since compensatory muscle activity no longer is required in a reconstructed knee. The reduction of TT may not be an appropriate objective in surgery on the ACL.

J Bone Joint Surg [Br] 2001;83-B:1098-1103.

Received 8 May 2000; Accepted after revision 22 May 2001

A common symptom of deficiency of the anterior cruciate ligament (ACL) is a buckling or 'giving way' during activity. This may vary considerably in frequency from once a year to daily. Although the exact mechanism of this instability remains unclear, it is thought to involve some form of abnormal anterior tibial movement, despite the

D. J. Beard, DPhil, Senior Fellow

D. W. Murray, FRCS, Professor of Orthopaedics

A. J. Price, FRCS, Research Fellow

J. L. Rees, FRCS, Research Fellow

C. A. F. Dodd, FRCS, Consultant Orthopaedic Surgeon

H. S. Gill, DPhil, Senior Fellow

Nuffield Orthopaedic Centre NHS Trust, Windmill Road, Headington, Oxford OX3 7LD, UK.

J. Alfaro-Adrián, FRCS, Orthopaedic Surgeon

Clinica La Zarzuela, Departmento de Traumatologia, 28023 Aravaca, Madrid, Spain.

Correspondence should be sent to Dr D. J. Beard.

(C)2001 British Editorial Society of Bone and Joint Surgery 0301-620X/01/811320\$2.00 documented lack of association between symptoms and passive tibial translation. ${ }^{1-3}$ The general understanding is that 'giving way' results from excessive sagittal slide of the femur on a fixed tibia, often with a rotatory component. The anatomy of the lateral compartment is often implicated in such a mechanism since it has two convex articular surfaces held in the correct position by the ACL. Rupture of this ligament therefore allows a degree of unconstrained movement between the two bones and a 'pivot shift' may often occur.

Management of deficiency of the ACL may involve an operation to replace the torn ligament with a graft in an attempt to reduce excess anterior tibial movement in the sagittal plane. ${ }^{4}$ Long-term studies examining the outcome after reconstruction have, with a few exceptions, shown it to be a successful procedure. ${ }^{5-10}$ Patients have a $90 \%$ to $95 \%$ chance of improvement in their symptoms and about a $40 \%$ chance of returning to their previous level and intensity of sport. ${ }^{11,12}$

The way in which reconstruction of the ACL achieves this outcome is not altogether clear. Undoubtedly, the restraint of tibial movement is of some importance, but to date, our understanding of cruciate-deficient kinematics has been obtained mainly by in vitro experiments, ${ }^{13-15}$ clinical assessment $^{16-18}$ and mathematical modelling. ${ }^{19-21}$ These more 'passive' or mechanical investigations may provide misleading information because they ignore the contribution of the sensorimotor system to stability of the knee. The co-ordination of muscle activity by the nervous system is vital to the normal functioning of a joint, and it is well documented that proprioceptive ability, muscle reaction time and muscle strength all contribute to stability. ${ }^{22-31}$ The fact that many patients continue to participate in sports despite a torn cruciate ligament ${ }^{32}$ emphasises the importance of sensorimotor activity.

The few in vivo studies which have examined the kinematics of patients with injuries to the ACL have predicted tibial translation from strain values measured using transducers embedded in the ligament. ${ }^{33,34}$ The only direct measurements of tibial translation in vivo have been achieved by arthrometers or electrogoniometers attached externally to the limb. ${ }^{35,36}$ While this line of research has been highly productive, both techniques reflect only activity under static conditions or with very controlled movement. ${ }^{37}$ 
We therefore know very little about how the bones in an ACL-deficient joint actually move in relation to each other during everyday activities. We need to know if there is increased translation during activity and whether any such functional instability can be corrected by surgery.

Using an in vivo method of investigation we have tested the hypothesis that the excess tibial translation (TT) evident during activity before surgery will be reduced by surgical reconstruction.

\section{Patients and Methods}

We obtained consent from 11 patients with unilateral deficiency of the ACL who were awaiting reconstruction. All had been diagnosed either at arthroscopy or by clinical examination in combination with MRI. Both techniques have been shown to be reliable and valid in the detection of rupture of the ACL. Patients were excluded if they had associated complex meniscal damage or collateral ligament injury, a symptomatic contralateral knee, symptoms in the ipsilateral hip, ankle or foot, a history of neuromuscular pathology, pain at the time of examination, or radiological grade-III or grade-IV degenerative changes.

The mean age of the patients was 29.7 years (SD 3.6) and the mean time from injury at the first assessment was 47 months (SD 30) indicating that the sample represented a chronically-injured population. Nine patients were men and six had injuries to the right knee. Six sustained their injury while playing soccer and others at squash, volleyball and netball. One patient was injured in a road-traffic accident and in one the mechanism was unknown. Five had severe instability, with at least three episodes of 'giving way' each week. In three the instability was moderate with 1 to 3 episodes each week, and in two it was minor with one episode per month. One patient had no observed instability, but underwent surgery because of a subjective feeling of instability which affected his level of activity. Six patients had reconstruction using a four-strand semitendinosus autograft and five had a bone-patellar-tendon-bone (B-PT-B) autograft. Four minor tears of the medial meniscus and two of the lateral meniscus were found at arthroscopy, and were resected. Before surgery eight patients had a positive Lachman test of grade 2 and three patients of grade 3. After operation eight patients had a negative Lachman test and three a Lachman grade 1 at a mean follow-up of 6.3 months (5 to 7$)$.

In all subjects gait was assessed using a three-dimensional Vicon 370 gait-analysis system (Oxford Metrics Ltd, Oxford, UK). This consists of infrared sensitive solid-state cameras which track passive retroreflective markers attached to anatomical landmarks and illuminated by an infrared strobe. The markers used were spheres with a diameter of $25 \mathrm{~mm}$ covered with retroreflective tape (Scotch-Lite Highgrain 7619; 3M UK Plc, Bracknell, UK). The surface of the tape consists of exposed glass spheres giving a non-specular surface which is resistant to inter- ference from ambient light. Seven cameras and infrared strobe lights, located with the cameras and illuminating the markers every $20 \mathrm{~ms}$, were used to record the spatial kinematics of each limb.

Measurements of the patients' height, weight, limb length, ankle and knee width and anterior superior iliac spine (ASIS)/trochanteric depth were taken. Markers were attached to the skin bilaterally over the ASIS, the centre of the greater trochanter, the lateral joint line of the knee, the centre of the lateral malleolus, the lateral aspect of the head of the fifth metatarsal, the posterior surface of the calcaneum and the midpoint between the posterior superior iliac spines. Two markers on $8 \mathrm{~cm}$ wands were applied to the leg at the level of the mid-thigh and mid lower skin. In addition, markers $15 \mathrm{~mm}$ in diameter were also placed over the proximal and distal pole of the patella, and the tibial tubercle.

Ground reaction forces during gait were recorded from two calibrated force plates (Kistler Instruments AG, Winterthur, Switzerland) set in the floor of a $9 \mathrm{~m}$ walkway in the gait laboratory within view of the cameras. Simultaneous data sampling from the cameras and force plates was at 50 and $400 \mathrm{~Hz}$, respectively. Data from the force plate were used to identify critical times during the gait cycle such as heel-strike and toe-off.

The system was calibrated before the measurements were made on each subject to define a common co-ordinate system for the three-dimensional video data. A residual RMS (root mean square) error in the output from a single camera, predominantly due to optical distortion of the camera lens, of less than $2 \mathrm{~mm}$ was deemed acceptable. Data were collected in quiet standing to ensure correct visualisation of the markers by the system and to establish an individual baseline for the patellar tendon angle (PTA) on each knee. The subjects were then asked to walk up and down the walkway several times at their own speed. These preliminary walks allowed for familiarisation with the laboratory and adjustment of the starting position to ensure strike upon the force plates with both feet in succession. Early attempts at recording the kinematics of the knee during more vigorous activities, such as running, were unsuccessful. An accurate strike of the forceplate was difficult to attain and markers were easily obscured or dislodged. The subject was then asked to walk while data were collected; three satisfactory trials were recorded for analysis.

After reconstruction and labelling the raw data were examined using Vicon Workstation V3.0 in animate mode which has a pop-up graphical facility and cursor. Characteristics of the gait cycle were identified using the synchronous force-plate data and values were extracted at various points of the cycle including heel-strike, the stance phase and the complete cycle. Any trials with incomplete data were discarded.

The PTA, the angle formed in the sagittal plane between the bisection of the long axis of the tibia (lateral malleolus 


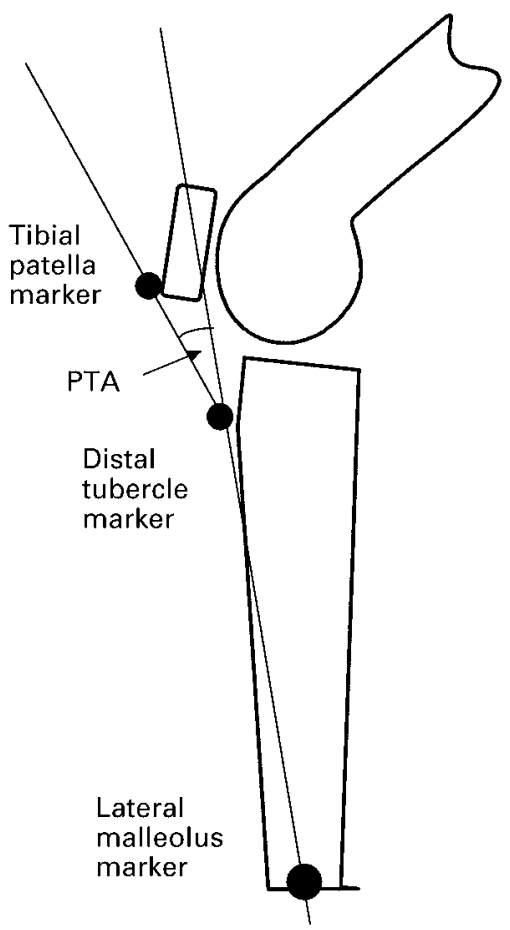

Fig. 1

Diagram showing the PTA.

to tibial tubercle) and the longitudinal axis of the patella tendon (the distal pole of the patella to tibial tubercle) was used to derive TT (Fig. 1). A smaller, more acute, angle is indicative of increasing anterior translation (Fig. 2). The mean value taken from three trials of the following variables was recorded for each limb on each patient: 1) the PTA in quiet standing; 2) the mean PTA over the gait cycle; 3) the mean PTA during stance phase; and 4) the PTA at heel-strike. Measurements were taken before and after reconstruction in both knees. Abnormal TT was determined by calculating the amount of translation occurring in the ACL-deficient limb relative to that of the control limb. A positive value indicates anterior translation relative to the control limb and a negative value posterior translation. This method of obtaining relative TT from the PTA does not allow absolute values to be calculated.

Relative TT (in mm) was determined using the following equation:

$$
\mathrm{TT}=\mathrm{N}\left(\operatorname{Sin} \mathrm{PTA}_{\mathrm{A}}-\operatorname{Sin} \mathrm{PTA}_{\mathrm{C}}\right)
$$

As PTA is also dependent on the angle of flexion of the knee, ${ }^{38}$ it was necessary to record knee flexion/extension. It is only possible to calculate abnormal TT from the difference in PTA between the limbs if it is first shown that there is no significant difference in the knee flexion angle between the limbs.

For reliability and validity trials we used a moving surrogate limb, in the shape of a plastic femur and tibia connected by a hinge, through known angular displace-

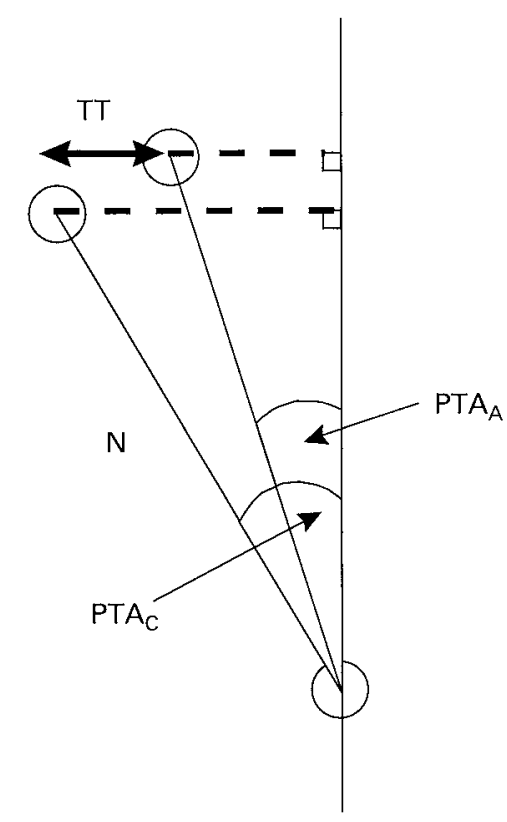

Fig. 2

Diagram showing the calculation of relative TT $\left(\mathrm{PTA}_{\mathrm{C}}=\right.$ patellar tendon angle of control limb; $\mathrm{PTT}_{\mathrm{A}}=$ patellar tendon angle operated/injured limb; $\mathrm{N}=$ distance between distal patellar and tibial tubercle markers).

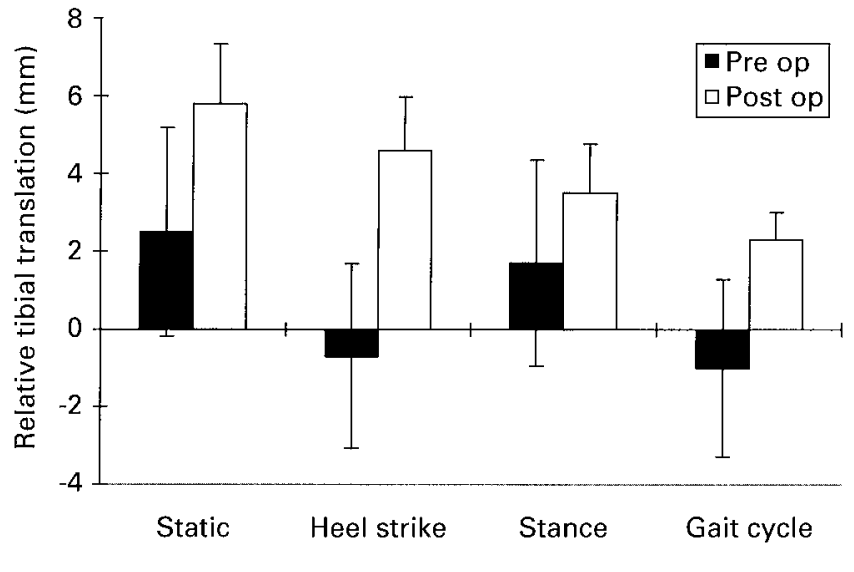

Fig. 3

The mean $( \pm \mathrm{SD})$ relative TT of the operated limb after reconstruction of the ACL for various gait parameters before and after operation.

ments. Three experiments were completed. A comparison was made between recordings made using the Vicon and an analogue method using a goniometer at four different set angles $\left(32^{\circ}, 23^{\circ}, 11^{\circ}\right.$ and $\left.6^{\circ}\right)$; the differences between measurements were $0.7^{\circ},-0.9^{\circ}, 0.1^{\circ}$ and $0^{\circ}$, respectively. The corresponding standard deviations of Vicon measurement, recorded for static trials at each of the above angles, were $0.06,0.07,0.05$ and 0.04 . Finally, a trial was done to examine the error of measurement associated with a moving limb. The difference in recorded angle between a static 
Table I. Mean (SD) changes in flexion angle (degrees) of the 11 knees before and after surgery

\begin{tabular}{lllllr}
\hline & Preop & Postop & Change & p value & 95\% CI \\
\hline Gait cycle & $2.8(7.6)$ & $0.4(5.4)$ & $2.4(10.0)$ & 0.47 & -9.1 to 4.3 \\
Stance phase & $-0.6(5.1)$ & $-0.4(4.7)$ & $-0.2(7.3)$ & 0.43 & -5.2 to 4.8 \\
Heel-strike & $1.8(6.0)$ & $-0.1(5.8)$ & $1.9(8.2)$ & 0.45 & -3.5 to 7.5 \\
\hline
\end{tabular}

Table II. Mean (SD) changes in PTA (degrees) during analysis of gait before and after operation in the 11 knees with reconstruction of the ACL and in the control knees

\begin{tabular}{llllllll}
\hline & Preoperation & & & & \multicolumn{2}{l}{ Postoperation } \\
\cline { 2 - 3 } & $\begin{array}{l}\text { Control } \\
\text { limb }\end{array}$ & $\begin{array}{l}\text { ACL } \text { injured } \\
\text { limb }\end{array}$ & p value & & $\begin{array}{l}\text { Control } \\
\text { limb }\end{array}$ & $\begin{array}{l}\text { ACL injured } \\
\text { limb }\end{array}$ & p value \\
\hline Static trial & $13.3(7.2)$ & $11.3(5.1)$ & 0.37 & & $13.7(5.7)$ & $9.1(2.3)$ & 0.04 \\
Heel-strike & $12.3(5.0)$ & $12.8(4.9)$ & 0.75 & & $11.2(6.0)$ & $7.4(5.0)$ & 0.003 \\
Stance phase & $9.9(4.1)$ & $8.6(5.1)$ & 0.55 & & $8.9(5.0)$ & $6.1(2.6)$ & 0.02 \\
Gait cycle & $9.0(3.3)$ & $9.9(4.1)$ & 0.65 & & $9.1(4.1)$ & $7.3(3.0)$ & 0.02 \\
\hline
\end{tabular}

Table III. Mean changes (SD) in the PTA (degrees) over time. A positive value indicates an increased difference between the control and ACL-injured limb after surgery because of the decrease in PTA of the injured/reconstructed $\operatorname{limb}$

\begin{tabular}{lllll}
\hline & Preop & Postop & Mean change & $\begin{array}{l}\text { 95\% CI for mean } \\
\text { change over time }\end{array}$ \\
\hline Static trial & $2.0(7.1)$ & $4.6(4.1)$ & $2.6(5.8)$ & -1.3 to 6.5 \\
Heel-strike & $-0.6(6.2)$ & $3.9(3.4)$ & $4.6(6.9)$ & 0.2 to 9.2 \\
Stance phase & $1.3(6.9)$ & $2.7(3.3)$ & $1.4(6.3)$ & -2.7 to 5.6 \\
Gait cycle & $-0.8(5.9)$ & $1.8(2.2)$ & $2.6(5.8)$ & -1.5 to 6.7 \\
\hline
\end{tabular}

Table IV. Mean (SD) relative TT (mm) of the 11 knees before and after operation

\begin{tabular}{lllll}
\hline & Preop & Postop & Mean change & $\begin{array}{l}\text { 95\% CI for } \\
\text { mean change }\end{array}$ \\
\hline Static trial & $2.5(8.9)$ & $5.8(5.1)$ & $3.3(7.3)$ & -1.6 to 8.3 \\
Heel-strike & $-0.7(7.9)$ & $4.6(4.6)$ & $5.8(8.9)$ & -0.2 to 11.8 \\
Stance phase & $1.7(8.8)$ & $3.5(4.2)$ & $1.8(8.0)$ & -3.6 to 7.2 \\
Gait cycle & $-1.0(7.6)$ & $2.3(2.8)$ & $3.3(7.9)$ & -2.0 to 8.6 \\
\hline
\end{tabular}

trial and during movement was $0.1^{\circ}$ (SD $\left.0.6^{\circ}\right)$. Overall measurement of angular displacement was considered to be accurate to within $\pm 0.8^{\circ}$. This is equivalent to an accuracy of measurement of $1 \mathrm{~mm}$ in the assessment of TT, assuming that there was no artefact from skin movement.

The knee flexion angle, the PTA and the relative TT were described using the differences between the limbs before and after operation (Tables I to III). A mean difference over time (preoperative to postoperative change) was calculated. We determined the $95 \%$ confidence intervals (CI) of the mean difference over time to indicate significance. A paired $t$-test was also used on the preoperative to postoperative values.

\section{Results}

Examination of the preoperative to postoperative changes in the knee flexion angle, as judged by the differences between the limbs, showed no significant differences in any gait parameter $(\mathrm{p}=0.47, \mathrm{p}=0.43, \mathrm{p}=0.45)$ (Table I). Having established that there was no significant change over time in the knee flexion angle we proceeded to derive TT from the differences in the PTA between the limbs.

Before surgery no significant difference was found but after surgery it was observed for every parameter of gait which was measured (Table II). The PTA of the operated limb was significantly less than that for the control limb, as reflected in the mean change before and after surgery (Table III). There was an increase in the mean difference in the PTA between the limbs after operation. For example, at heel-strike, the difference in PTA increased from a minimal difference $\left(-0.6^{\circ}\right)$ to nearly $4^{\circ}$ after surgery, a mean change of $4.6^{\circ}$. Despite the changes in the PTA over time being significant only at heel-strike, all remaining parameters of gait showed a reduction in the PTA after reconstruction. The lack of statistical significance is due to the limited power of the study because of its low sample size, and some potential type-II error is acknowledged. 
In accordance with the relationship between the PTA and TT, the calculated relative or abnormal TT mirrored the changes in the PTA. Before operation there was no significantly abnormal TT for any activity studied. After the operation an increase in the relative TT was found in each parameter of gait (Table IV). Again the $95 \%$ CI shows that the effect is observed rather than statistically significant. Changes in TT are shown graphically in Figure 3. No difference was found between the patients who had undergone either a B-PT-B or a hamstring procedure.

\section{Discussion}

In a mechanical context, the primary objective of reconstructive surgery of the ACL is to reduce TT in the sagittal plane. ${ }^{4}$ It is assumed that the subsequent improvement in stability and function of the knee found after surgery ${ }^{5-7,9,10}$ is achieved by reducing the amount of available tibial movement. The results of this in vivo study cast doubt on such reasoning. No obvious pattern of anterior translation was found before reconstruction; anterior translation increased rather than decreased after this procedure.

The ability of patients with an ACL injury to control TT during activity, despite having obvious passive laxity, is well documented. No correlation has been shown between symptoms and laxity, and it is well known that muscular activity has an important role in stabilising the cruciatedeficient knee. ${ }^{39}$ Both mathematical modelling ${ }^{21}$ and studies of muscular activity have confirmed that excess TT can be restricted by contraction of the hamstring muscles. ${ }^{40-43}$ Furthermore, specific ACL rehabilitation exercises have been shown to enhance sensorimotor function and increase the dynamic stability of the knee. ${ }^{44}$ Since most patients in our study had undergone rehabilitation before reconstruction, the lack of translation before surgery may be due to compensatory muscle activity.

The observation that translation in the operated limb increased after surgery was unexpected and an explanation is less obvious. It suggests that reconstruction makes patients worse. This, however, is clearly refuted in terms of symptoms and function. Despite the limited follow-up, qualitative evaluation at six months indicated that patients in our study had a successful outcome. This new observation of increased in vivo translation after surgery, with a satisfactory outcome, contradicts current thinking and requires further consideration.

Our explanation for the findings is based on alterations in muscle activity around the knee. After surgery, there may be a reduction in the characteristic compensatory activity of the hamstring muscles which has been previously described. ${ }^{40,43,45,46}$ This decreased activity is an indirect effect of increasing the mechanical stability of the knee. The most likely mechanism is that optimal sensorimotor function is regained by restoring the kinematics. Since proprioceptive information is more meaningful from a stable knee, muscles can be activated on a 'demand only' basis. The need for constant compensatory hamstring contraction is therefore eradicated and the tibia shows increased, yet controlled, anterior excursion. Cruciate reconstruction therefore represents the re-establishment of a critical element in the control system for stability rather than the straightforward replacement of a passive restraint to movement.

One other possible explanation of the increased translation is postoperative atrophy and weakness of the muscles. This, however, is less likely since our study sample included patients undergoing both B-PT-B and hamstring procedures.

Some methodological issues warrant discussion. First, the derivation of TT from the PTA is only approximate as the inclination of the tibial plateau is not perpendicular to the marker-defined tibial axis. Secondly, all surface-mounted skin markers used for gait analysis are prone to artifact from skin movement. Our calculations of TT are based on the AP movement of the markers on the tibial tuberosity and lower pole of the patella which are influenced minimally by skin movement. ${ }^{47}$ Errors are further minimised by basing the assessment on the relative movement between the injured and control limbs. Postoperative shortening of the patellar tendon is another potential source of error; ${ }^{48}$ but there was no evidence of shortening in our group of patients. A further issue involves the plane and type of activity examined. Knee instability is a multiplane phenomenon and information about tibial rotation, particularly during more stressful activities, is required. Further corroborative studies are planned which will include an electromyographic assessment and measurements of tibial rotation during running and cutting. A final point refers to the limited power of the study. It should be noted that, despite the potential clinical importance, some of the results indicate observed, but not necessarily statistically significant change.

Reconstruction of the ACL is effective in restoring function and it is widely believed that a successful outcome is achieved by reducing TT. Our study questions this assertion. Previous evidence, together with our in vivo results, suggests that symptoms and laxity are unrelated. The main clinical message from our observations pertains to the objective of cruciate surgery. We believe that the aim of operation should be to ensure sufficient mechanical integrity so that the knee may be stabilised by active muscular activity, rather than to reduce passive TT.

We wish to thank the Wishbone Trust for their support of this project and J.J. O'Connor, P. J. Kyberd, M. Harrington and P. Oppold for their assistance.

No benefits in any form have been received or will be received from a commercial party related directly or indirectly to the subject of this article.

\section{References}

1. Snyder-Mackler L, Fitzgerald GK, Bartolozzi AR 3rd, Ciccotti MG. The relationship between passive joint laxity and functional outcome after anterior cruciate ligament injury. Am J Sports Med $1997 ; 25: 191-5$ 
2. Forster IW, Warren-Smith CD, Tew M. Is the KT1000 knee ligament arthrometer reliable? J Bone Joint Surg [Br] 1989;71-B:8437 .

3. Bray R, Dandy DJ. Meniscal lesions and chronic anterior cruciate ligament deficiency: meniscal tears occurring before and after reconstruction. J Bone Joint Surg [Br] 1989;71-B:128-30.

4. Frank CB, Jackson DW. The science of reconstruction of the anterior cruciate ligament. J Bone Joint Surg [Am] 1997;79-A:1556-76.

5. Andersson C, Gillquist J. Treatment of acute isolated and combined ruptures of the anterior cruciate ligament: a long-term follow up study. Am J Sports Med 1992;20:7-12.

6. Engstrom B, Wredmark T, Westblad P. Patellar tendon or LeedsKeio graft in the surgical treatment of anterior cruciate ligament ruptures: intermediate results. Clin Orthop 1993;295:190-7.

7. Anderson AF, Snyder RB, Lipscomb AB. Anterior cruciate ligament reconstruction using the semitendinosus and gracilis tendons augmented by the Losee iliotibial band tenodesis. Am J Sports Med 1994;22:620-6.

8. Daniel DM, Stone ML, Dobson BE, et al. Fate of the ACL-injured patient: a prospective outcome study. Am J Sports Med 1994;22:632-44.

9. Shelbourne KD, Klootwyk TE, Wilckens JH, De Carlos MS. Ligament stability two to six years after anterior cruciate ligament reconstruction with autogenous patellar tendon graft and participation in accelerated rehabilitation program. Am $J$ Sports Med 1995;23:575-9.

10. Heier KA, Mack DR, Moseley JB, Paine R, Bocell JR. An analysis of anterior cruciate ligament reconstruction in middle-aged patients. Am J Sports Med 1997;25:527-32.

11. Dye SF, Wojtys EM, Fu FH, Fithian DC, Gillquist J. Factors contributing to function of the knee joint after injury or reconstruction of the anterior cruciate ligament. J Bone Joint Surg [Am] 1998;80-A:1380-93.

12. Beard DJ, Banff M, Godfrey J, Breckenridge J. Predictive validity of clinical tests for ACL reconstruction. 9th Cong Europ Society of Sports Traumatology, Knee Surgery and Arthroscopy. London, UK, 2000

13. Grood ES, Suntay WJ, Noyes FR, Butler DL. Biomechanics of the knee-extension exercise: effect of cutting the anterior cruciate ligament. J Bone Joint Surg [Am] 1984;64-A:725-34.

14. Good L, Askew MJ, Boom A, Melby A III. Kinematic in-vitro comparison between the normal knee and two techniques for reconstruction of the anterior cruciate ligament. Clin Biomech 1993;8:243-9.

15. Markolf KL, Gorek JF, Kabo M, Shapiro MS. Direct measurement of resultant forces in the anterior cruciate ligament. J Bone Joint Surg [Am] 1990;72-A:557-67.

16. Andersson C, Gillquist J. Instrumented testing for evaluation of sagittal knee laxity. Clin Orthop 1990;256:178-84.

17. Daniel DM. Assessing the limits of knee motion. Am J Sports Med 1991;19:139-47.

18. Kim S-J, Kim H-K. Reliability of the anterior drawer test, the pivot shift test, and the Lachman test. Clin Orthop 1995;317:237-42.

19. O'Connor JJ. Can muscle co-contraction protect knee ligaments after injury or repair? J Bone Joint Surg [Br] 1993;75-B:41-8.

20. Zavatsky A, Beard DJ, O'Connor J. Cruciate ligament loading during isometric muscle contractions: a theoretical basis for rehabilitation. Am J Sports Med 1994;22:418-23.

21. Imran A, O'Connor JJ. Control of knee stability after ACL injury or repair: interaction between hamstrings contraction and tibial translation. Clin Biomech 1998;13:153-62.

22. Barrack RL, Skinner HB, Buckley SL. Proprioception in the anterior cruciate deficient knee. Am J Sports Med 1989;17:1-6.

23. Barrett DS. Proprioception and function after anterior cruciate ligament reconstruction. J Bone Joint Surg [Br] 1991;73-B:833-7.

24. Corrigan JP, Cashman WF, Brady MP. Proprioception in the cruciate deficient knee. J Bone Joint Surg [Br] 1992;74-B:247-50.

25. Lephart SM, Kocher MS, Fu FH, Borsa BA, Harner CD. Proprioception following anterior cruciate ligament reconstruction. J Sports Rehabil 1992;1:188-96.
26. Harter RA, Osternig LR, Singer KM. Knee joint proprioception following anterior cruciate ligament reconstruction. J Sports Rehabil 1992;1:103-10

27. Carter ND, Jenkinson TR, Wilson D, Jones DW, Torode AS. Joint position sense and rehabilitation in the anterior cruciate ligament deficient knee. Br J Sports Med 1997;31:209-12.

28. Jerosch J, Prymka M. Knee joint proprioception in normal volunteers and patients with anterior cruciate ligament tears, taking special account of the effect of a knee bandage. Arch Orthop Trauma Surg 1996;115:162-6.

29. Kannus P. Ratio of hamstring to quadriceps femoris muscles' strength in the anterior cruciate ligament insufficient knee: relationship to longterm recovery. Physical Ther 1988;68:961-5.

30. Beard DJ, Kyberd PJ, O'Connor JJ, Fergusson CM, Dodd CAF. Reflex hamstring contraction latency in anterior cruciate ligament deficiency. J Orthop Res 1994;12:219-28.

31. Wojtys EM, Huston LJ. Neuromuscular performance in normal and anterior cruciate ligament-deficient lower extremities. Am J Sports Med 1994;22:89-104.

32. Noyes FR, Matthews DS, Mooar PA, Grood ES. The symptomatic anterior cruciate-deficient knee; part 2: the results of rehabilitation, activity modification, and counselling on functional disability. $J$ Bone Joint Surg [Am] 1983;65-A:163-74.

33. Beynnon B, Howe JG, Pope MH, Johnson RJ, Fleming BC. The measurement of anterior cruciate ligament strain in vivo. Int Orthop 1992;16:1-12.

34. Fleming BC, Beynnon BD, Renstrom PA, et al. The strain behavior of the anterior cruciate ligament during bicycling: an in vivo study. Am J Sports Med 1998;26:109-18.

35. Fleming B, Beynnon B, Nichols C, Johnson R, Pope M. An in vivo comparison of anterior tibial translation and strain in the anteromedial band of the anterior cruciate ligament. J Biomech 1993;26:51-8.

36. Vergis A, Gillquist J. Sagittal plane translation of the knee during stair walking: comparison of healthy and anterior cruciate ligamentdeficient subjects. Am J Sports Med 1998;26:841-6.

37. Beynnon BD, Johnson RJ, Fleming BC, et al. The strain behaviour of the anterior cruciate ligament during squatting and active flexionextension: a comparison of an open and a closed kinetic chain exercise. Am J Sports Med 1997;25:823-9.

38. Gill HS, O'Connor JJ. Biarticulating two-dimensional computer model of the human patellofemoral joint. Clin Biomech 1996;11:81-9.

39. More RC, Karras BT, Neiman R, Fritschy D, et al. Hamstrings: an anterior cruciate ligament protagonist: an in vitro study. Am J Sports Med 1993;21:231-7.

40. Kälund S, Sinkjaer T, Arendt-Nielson L, Simonsen O. Altered timing of hamstring muscle action in anterior cruciate ligament deficient patients. Am J Sports Med 1990;18:245-8.

41. Hirokawa S, Solomonow M, Luo Z, Lu Y, D'Ambrosia RD. Muscular co-contraction and control of knee stability. J Electromyog Kin 1991;1:199-208

42. Grabiner MD, Weiker GG. Anterior cruciate ligament injury and hamstrings coactivation. Clin Biomech 1993;8:215-9.

43. Beard DJ, Soundarapandian RS, O'Connor JJ, Dodd CAF. Gait and electromyographic analysis of anterior cruciate ligament deficient subjects. Gait and Posture 1996;4:83-8.

44. Beard DJ, Dodd CAF, Trundle H, Simpson AHRW. Proprioceptive enhancement for anterior cruciate ligament deficiency: a prospective randomised trial of two physiotherapy regimes. J Bone Joint Surg [Br] 1994;76-B:654-9.

45. Sinkjaer T, Arendt-Neilson L. Knee stability and muscle coordination in patients with anterior cruciate ligament injuries: an electromyographic approach. J Electro Myog Kin 1991;1:209-17.

46. Shiavi R, Zhang LQ, Limbird T, Edmondstone MA. Pattern analysis of electromyographic linear envelopes exhibited by subjects with uninjured and injured knees during free and fast speed walking. J Orthop Res 1992;10:226-36.

47. Harinderjit G, Beard DJ, Murray DW, Dodd CAF. An accurate measurement of tibiofemoral motion during functional activity. Proc 7th European Society of Sports Traumatology, Knee Surgery and Arthroplasty (ESSKA) Budapest, Hungary, 1996.

48. Dandy DJ, Desai SS. Patellar tendon length after anterior cruciate ligament reconstruction. J Bone Joint Surg [Br] 1994;76-B:198-9. 